\title{
Primary Spontaneous Pneumothorax: Towards Outpatient Treatment and Abandoning Chest Tube Drainage
}

\author{
Julius Janssen $^{\text {a }} \quad$ Giuseppe Cardillo ${ }^{b}$ \\ ${ }^{a}$ Department of Pulmonary Diseases B01, Canisius Wilhelmina Hospital, Nijmegen, The Netherlands; \\ bUnit of Thoracic Surgery, Azienda Ospedaliera San Camillo Forlanini, Rome, Italy
}

\section{Key Words}

Pneumothorax · Pleural disease - Thoracoscopy

\begin{abstract}
The initial treatment of primary spontaneous pneumothorax is not standardized throughout the world. Although aspiration is less painful and requires less hospitalization than chest tube drainage does, the latter is still frequently used as the initial treatment. After a recurrence or failure of aspiration, chest tube drainage, again, is often the procedure of choice although VATS or thoracoscopy and talc poudrage have been proven to be much more effective. For the surgical treatment of recurrent pneumothorax, the role of routine resection of blebs and nonruptured bullae still needs to be assessed. Pleurodesis (chemical or mechanical) should be the standard treatment in a surgical procedure.
\end{abstract}

Copyright $\odot 2011$ S. Karger AG, Basel

\section{Initial Treatment}

There is no consensus on the treatment of primary spontaneous pneumothorax (PSP). Guidelines have been developed $[1,2]$, but they show poor agreement in terms of the size classification of SP and initial treatment $[3,4]$. Besides, deviation from published guidelines in the management of SP is frequent and widespread [5].

The traditional initial treatment of PSP is chest tube drainage using a relatively large $(20 \mathrm{Fr}$ ) bore chest tube attached to a water seal suction device, which makes hospitalization and immobilization necessary. According to ACCP guidelines, which date back to 2001, this is still the treatment of choice.

Simple aspiration, although rarely warranted according to ACCP guidelines, has gained popularity in recent years and is advocated as a primary technique for the management of SP in all patients requiring intervention according to the BTS [2].

Conservative treatment is appropriate in cases of small PSP with limited clinical symptoms, according to all guidelines, although there is no consensus on the definition of small PSP [3].

Although the technique drew more attention and gained popularity after publication of the randomized trial of Noppen et al. [6] it is still being underutilized [5]. However, this randomized prospective study compared aspiration and chest tube drainage and found no difference in the immediate success rate, early failure after 1 week, or recurrence after 1 year [6]. There was a signifi-

\section{KARGER}

Fax +41613061234

E-Mail karger@karger.ch

www.karger.com
(C) 2011 S. Karger AG, Basel

$0025-7931 / 11 / 0882-0201 \$ 38.00 / 0$

Accessible online at:

www.karger.com/res
Julius P. Janssen

Department of Pulmonary Diseases B01, Canisius Wilhelmina Hospital Postbox 9015

NL-6500 GS Nijmegen (The Netherlands)

Tel. +31 243658755 , E-Mail j.janssen@cwz.nl 
cant difference in the need for hospitalization in favor of aspiration. Moreover, aspiration does not have the drawbacks of drainage such as scar formation, pain, anxiety, and limited mobility.

Another treatment option is the use of a small pleural catheter $(8 \mathrm{Fr})$ or a pigtail catheter, combined with a oneway valve. An advanced study showed promising results with success rates of $66 \%$ at $24 \mathrm{~h}$ and $85 \%$ at 1 week. Patients remained ambulant and hospital stay was reduced to an average of 2.3 days [7].

Recent studies have shown that, with increased use of aspiration, PSP can be treated more frequently as an emergency department-based disease instead of an inhospital disease, with positive effects on patient comfort and the costs of medical care.

\section{Treatment in Case of Failure or Recurrence}

There is no consensus about the treatment of PSP after recurrence or failure of treatment. Treatment options can vary from chest tube drainage, thoracoscopy and talc pleurodesis, and VATS with or without bleb resection to thoracotomy $[6,8]$. Chest tube drainage is used most frequently in cases of recurrence but for unclear reasons. A recent uncontrolled retrospective study comparing VATS and chest tube drainage for recurrent PSP showed a complication rate of $27.3 \%$ and an overall failure rate of $40.9 \%$ for chest tube drainage. For VATS these figures were, respectively, 6.7 and $3.3 \%$.

In a randomized study comparing chest tube drainage to thoracoscopy and talc poudrage [9], the total costs of hospitalization did not differ between the 2 treatments. One months after discharge from the hospital there was no significant difference in residual pain or full working ability between the 2 groups. After 5 years of follow-up, the recurrence rate was 5\% in the thoracoscopy and talcage group versus $34 \%$ in the chest tube drainage group.

\section{Surgical Treatment of Pneumothorax}

Patients with a second episode of pneumothorax have a 30-60\% chance of having a third episode, and the probability of having a fourth episode reaches $75 \%$ if the patient has suffered 3 previous pneumothoraces. Consequently, surgery is usually warranted in cases of a first recurrence of pneumothorax as well as in cases of a first contralateral pneumothorax, bilateral SP, spontaneous hemothorax, persistent air leak, or failure to completely reexpand after drainage; professions at risk are clear indications for surgery $[10,11]$. The timing of referral for surgery after a persistent air leak has no evidence-based justification, but a widely advocated cutoff point of 4 days is recommended by the ACCP and one of 5 days is recommended by the BTS $[1,2]$. Recently, some authors have suggested early operation.

The type of surgery is still under debate even if the great majority of the most recent reports favor the minimally invasive VATS approach [11]. Comparing randomized trials, VATS can be associated with a shorter length of hospital stay (reduction ranged from 1 to 4.2 days) and less pain or use of pain medication, as well as with a better pulmonary gas exchange in the postoperative period compared to thoracotomy with a comparable complication profile and success rate [11]. A better cosmetic result has also been stressed in VATS papers [10]. A recently published paper compared the recurrence rates of VATS versus open surgery in randomized and nonrandomized trials, with a total of 3,466 patients in 29 studies (4 randomized and 25 nonrandomized), and found a 4 -fold increase in the success rate when a similar pleurodesis was done by VATS [12]. The drawback is that most of the papers are older (15 had been reported by 1997) and underpowered [13].

The VATS approach follows the same rules of the open approach: a ruptured bulla should always be resected and not ligated [10]. The role of routine resection of bullae or a dystrophic lung apex needs further clarification. Pleurodesis must always be added, and there are 3 options: pleurectomy, abrasion, and talc poudrage. The safety of such tools has been clearly shown $[10,14,15]$, and the choice is a matter of personal experience. In the largest report of VATS talc poudrage, the recurrence rate was 1.73 out of 805 patients with a mean follow-up of 52.5 months [11]. The recent proposal of a preventive VATS contralateral prophylactic treatment in the same operation has no role in clinical practice [16].

\section{Conclusion}

There is a lack of international agreement on the treatment of pneumothorax, which is mainly based on the absence of well-performed randomized studies. Consequently, there is little high-quality evidence to guide decision making in PSP.

There is growing evidence that the first episode of PSP can be treated with simple aspiration in the emergency department without hospitalization. Chest tube drainage 
is an invasive hospital-based procedure with no advantage over aspiration in terms of complications or the recurrence rate, and it should be abandoned as a standard form of treatment.

The way forward is outpatient treatment by simple aspiration in first and uncomplicated episodes of PSP. Inhospital treatment should be reserved for invasive procedures that aim for a reduction of recurrence, such as thoracoscopy/VATS with talc poudrage, or VATS with pleurectomy. The role of the routine removal of nonrup- tured blebs and bullae is still unclear and needs to be elucidated in future surgical studies.

Recurrent and complicated pneumothorax should be treated via surgery with pleurodesis or talc poudrage via medical thoracoscopy. VATS appears to be the approach of choice compared to open thoracotomy. Pleurodesis needs to be always added to the procedure, and the choice between the most common procedures is a matter of personal experience even if the biggest nonrandomized experience shows a clear advantage for talc poudrage [11].

\section{References}

1 Baumann M, Strange C, Heffner J, et al: Management of spontaneous pneumothorax: an American College of Chest Physicians Delphi consensus statement. Chest 2001;119:590-602.

2 Macduff A, Arnold T, Harvey J: Management of spontaneous pneumothorax: British Thoracic Society Pleural Disease Guideline 2010. Thorax 2010;65(suppl 2):ii18-ii31.

$>3$ Kelly AM, Druda D: Comparison of size classification of primary spontaneous pneumothorax by three international guidelines: a case for international consensus? Respir Med 2008;102:1830-1832.

4 Gaudio M, Hafner J: Simple aspiration compared to chest tube insertion in the management of primary spontaneous pneumothorax. Ann Emerg Med 2009;54:548-560.

$>5$ Kelly AM, Clooney M: Deviation from published guidelines in the management of primary spontaneous pneumothorax in Australia. Intern Med J 2008;38:64-67.
6 Noppen M, Alexander P, Driesen P, et al: Manual aspiration versus chest tube drainage in first episodes of primary spontaneous pneumothorax: a multicenter, prospective, randomized pilot study. Am J Respir Crit Care Med 2002;165:1240-1244.

$>7$ Marquette CH, Marx A, Leroy S. Simplified stepwise management of primary spontaneous pneumothorax: a pilot study. Eur Respir J 2006;27:470-476.

$\checkmark 8$ Chen JS, Hsao-Hun H, Kung-Tsao T, et al: Salvage for unsuccessful aspiration of primary pneumothorax: thoracoscopic surgery or chest tube drainage? Ann Thorac Surg 2008;85:1908-1913.

9 Tschopp JM, Boutin C, Astoul P: Talcage by medical thoracoscopy for primary spontaneous pneumothorax is more cost-effective than drainage: a randomized study. Eur Respir J 2002;20:1003-1009.

10 Cardillo G, Facciolo F, Giunti R, Gasparri R, Lopergolo M, Orsetti R, Martelli M: Videothoracoscopic treatment of primary spontaneous pneumothorax: a 6-year experience. Ann Thorac Surg 2000;69:357-361.

$\checkmark 11$ Cardillo G, Carleo F, Giunti R, Carbone L, Mariotta S, Salvadori L, Petrella L, Martelli M: Videothoracoscopic talc poudrage in primary spontaneous pneumothorax: a singleinstitution experience in 861 cases. J Thorac Cardiovasc Surg 2006;131:322-328.
2 Treasure T: Minimal access surgery for pneumothorax. Lancet 2007;370:294-295.

13 Barker A, Maratos EC, Edmonds L, et al: Recurrence rates of video-assisted thoracoscopic versus open surgery in the prevention of recurrent pneumothoraces: a systematic review of randomised and non-randomised trials. Lancet 2007;370:329-335.

14 Noppen M: Who's (still) afraid of talc? Eur Respir J 2007;29:619-621.

15 Cardillo G, Carleo F, Carbone L, Di Martino M, Salvadori L, Ricci A, Petrella L, Martelli M: Long-term lung function following videothoracoscopic talc poudrage for primary spontaneous recurrent pneumothorax. Eur J Cardiothorac Surg 2007;31:802-805.

16 Chou SH, Li HP, Lee JY, Chang SJ, Lee YL, Chang YT, Kao EL, Dai ZK, Huang MF: Is prophylactic treatment of contralateral blebs in patients with primary spontaneous pneumothorax indicated? J Thorac Cardiovasc Surg 2010;139:1241-1245. 